\title{
Non-aspectual Case and Duration/Frequency Adverbials in Korean
}

Kyumin $\mathrm{Kim}^{+}$

Cheongju University

\begin{abstract}
Across languages, certain types of adverbials, such as duration and frequency adverbials, have been identified as being accusative case-marked just like objects. As case is canonically assigned to nominal arguments such as objects, central questions have been whether the case on these adverbials is syntactic like that on objects, and how to characterize the realization of accusative case on adverbials. In addressing these questions, this paper proposes that accusative case on adverbials is syntactic. In particular, what this paper newly proposes is that accusative case is not aspectual, and thus not licensed by an aspectual functional head (e.g., Asp), unlike in some previous studies of Korean and other languages. This paper provides a minimalist syntactic analysis in which accusative case is the result of an Agree relation between an adverbial and a functional head that introduces an external argument. In the course of executing this analysis, the paper clarifies the contribution of animacy and agency to the realization of accusative case.
\end{abstract}

Keywords: duration adverbial, frequency adverbial, case, external argument, agent, animacy

\section{Introduction}

Certain non-subcategorized adverbials are well observed to be case-marked across languages. For example, in Korean, duration and frequency adverbials that are nominals can be accusative marked (e.g., Kim and Maling 1993, Wechsler and Lee 1996, Maling et al. 2001 among many others), which is also found in languages such as Russian and Finnish (Pereltsvaig 2000; Kylie 2007). An example from Korean is presented in (1).

(1) Tom-i mikwuk-ul twu pen-ul

Tom-NOM America-ACC two times-ACC

'Tom visited America two times.' pangmwun-hay-ss-ta. visit-do-PAST-DEC (Wechsler and Lee 1996)

\footnotetext{
${ }^{\dagger}$ Corresponding author: kyumin.kim2012@gmail.com
} 
Just like arguments of verbs, such as the object mikwuk 'America' in (1), are accusative marked, a non-subcategorized adverbial of the verb, twu pen 'two times', is accusative marked. In standard case theory from the Case Filter (Chomsky 1981) to Minimalism (Chomksy 1995, 2000), a nominal argument, but not an adverbial, has been treated as receiving case via whichever means available in a given theoretical framework. Thus, the fact that an adverbial can be case-marked as in (1) has been the center of theoretical research; for example, it raises the question of whether case on adverbials is syntactic, and if so, how case can be realized on an adverbial. In the literature, case on the type of adverbial in (1) has been viewed to be syntactic, not lexical or inherent (e.g., Kim and Maling 1993, Wechsler and Lee 1996, Maling et al. 2001, Sohng 2004). What this means is that case marking on the adverbial is realized in the same manner as it is realized on an object argument.

This paper addresses two questions regarding accusative case-marked adverbials such as in (1) by examining data in Korean. One is how to syntactically characterize the realization of accusative case on the adverbials, given that structural case on an object can be either aspectually or non-aspectually realized. This paper shows that accusative case on the adverbials in Korean is non-aspectual: there is no correlation between accusative case and aspectual properties of an event, e.g., boundedness, which has been proposed for other languages, e.g., Russian and Finnish (Pereltsvaig 2000). This paper proposes that accusative case on duration or frequency adverbials is realized via Agree (Chomksy 2000, 2001) between a functional head that introduces an external argument and an adverbial that merges in Asp(ect)P. However, unlike in Chomsky (2000), in implementing Agree with respect to a relevant adverbial in Korean, I assume feature valuation occurs in the probe as in Bošković (2007) (see section 4).

Another question that this paper addresses is the role of animacy with respect to accusative case on duration and frequency adverbials. In certain cases where otherwise accusative case is not available, animacy of the subject is recognized as a factor for the realization of accusative case on these adverbials (e.g., Kim and Maling 1993, Maling et al. 2001; Lee 2017). However, this paper shows that animacy cannot be the sole factor, but should be considered together with respect to the type of eventuality denoted by the predicate. In particular, as with Folli and Harley (2007), an entity can be considered as an agent external argument when it has a 'teleological capability' to carry out the eventuality denoted by the predicate. Under this view, for example, an inanimate entity can be viewed as an agent external argument as far as it has an inherent ability to initiate the relevant event in question. Accusative 
case is available on a duration or frequency adverbial that occurs with such an inanimate subject.

The proposed account in this paper is consistent with previous studies (e.g., Kim and Maling 1993; Wechsler and Lee 1996; Maling et al. 2001) in that the presence of an external argument is crucial to the realization of accusative case on the adverbials. Unlike the previous studies, however, this paper provides a formal account of the realization of accusative case on the adverbials in minimalistic syntax. In so doing, it clarifies the role of accusative case on adverbials in Korean: accusative case is non-aspectual, although the adverbials are themselves semantically aspectual. This paper also clarifies the role of animacy with respect to accusative case: animacy of a subject plays a role in having accusative case realized, but only when the subject can be considered to possess teleological capability with respect to a given eventuality denoted by the predicate.

This paper is organized as follows: section 2 provides basic data of duration and frequency adverbials. Section 3 shows that accusative case in Korean is non-aspectual, unlike in other languages. Section 4 proposes an account for the realization of accusative case in terms of Agree. Section 5 concludes the paper.

\section{Basic Data on Duration and Frequency Adverbials}

This section discusses basic properties of duration and frequency adverbials that form the basis for the discussion in the rest of the paper. In Korean, as noted in the previous section, duration and frequency adverbials can be case-marked similar to a nominal argument such as an object, as illustrated in (2):1)
(2) a. Tom-i
kongpwu-lul
twu sikan-tongan-ul
hay-ss-ta.
Tom-NOM study-ACC
two hours-period-ACC
do-PAST-DEC
'Tom studied for two hours.'

1) An adverbial that indicates a distance measure can be also accusative case marked, as illustrated in

(i) with the adverbial isip mail 'twenty miles':
(i) Tom-i
isip
mail-ul
tali-ess-ta.
Tom-NOM twenty
miles-ACC
run-PAST-DEC
(Wechsler and Lee 1996)

In this paper, the discussion is illustrated with duration and frequency adverbials, but the proposal made can be also extended to distance measure adverbials. 
b. Tom-i mikwuk-ul twu pen-ul pangmwun-hay-ss-ta. Tom-NOM America-ACC two times-ACC visit-do-PAST-DEC 'Tom visited America two times.'

(Wechsler and Lee 1996)

In (2a), a duration adverbial twu sikan-tongan 'for two hours' is accusative marked, like the object kongpwu 'study' in the same sentence. In (2b), a frequency adverb twu pen 'two times' is accusative marked, like the object mikwuk 'America' in the same clause. Case marking on duration and frequency adverbials is not obligatory but optional (Y.J. Kim 1990; Maling et al. 2001; Lee 2017), as exemplified in (3). Following Maling et al. (2001), I assume that discourse factors govern the presence and absence of case on duration and frequency adverbials, and this paper is concerned with case-marked duration and frequency adverbials only.2)

$\begin{array}{lllll}\text { (3) Inho-ka } & \text { TV-lul } & \text { sey } & \text { sikan(-lul) } & \text { po-ass-ta } \\ \text { Inho-NOM } & \text { TV-ACC } & 3 & \text { hour (-ACC) } & \text { watch-PAST-DEC } \\ \text { 'Inho watched TV for three hours.' } & & \text { (Maling et al. 2001) }\end{array}$

In the rest of this paper, the two types of adverbials are referred to as $\mathrm{D}$ (uration)/ $\mathrm{F}$ (requency) adverbials, as employed in most of the literature on these adverbials in Korean.3)

Unlike D/F adverbials, there are other types of adverbials that cannot be case marked, as illustrated in (4) (Wechsler and Lee 1996):

(4) a. Tom-i

coyonghi $\left({ }^{*}-1 \mathrm{lul}\right)$

wa-ss-ta.

Tom-NOM silently(-*ACC)

come-PAST-DEC

'Tom approached silently.'

b. Tom-i

$$
\text { siktang-eyse }\left({ }^{*}-1 \mathrm{lul}\right)
$$

pap-ul

mek-ess-ta.

Tom-NOM restaurant-at(-*ACC)

meal-ACC

eat-PAST-DEC

'Tom ate meals at the restaurant.'

2) This paper does not pursue a question of how case markers become available on duration and frequency adverbials, which is well beyond the scope of this paper. As for discourse factors, in Jun (2000), it is proposed that case marked adverbials may have a focus reading. For more detail, see Jun (2000).

3) In Wechsler and Lee (1996), F adverbials are referred as multiplicative adverbials. The specific name used is not crucial to the proposal made in this paper. 
The adverbial coyonghi 'silently' in (4a) is a manner adverbial and the adverbial siktang-eyse 'at the restaurant' in (4b) is a locating adverbial. As indicated in (4), they cannot be accusative marked. This type of adverbial will be mentioned in the discussion to follow in comparison to $\mathrm{D} / \mathrm{F}$ adverbials, but this paper does not pursue an analysis of them.4)

In addition to accusative, $\mathrm{D} / \mathrm{F}$ adverbials can be nominative marked when they appear with certain predicates, such as simplex psychological verbs or dispositiondenoting adjective predicates (e.g., Kim and Maling 1993; Maling et al. 2001; Lee 2017). These are illustrated in (5):

(5)
a. Na-nun Mina-ka
twu pen-i
miw-ess-ta.
I-TOP Mina-NOM two time-NOM dislike (is distasteful)-PAST-DEC 'I disliked Mina two times.'
b. Aki-nun thayena-nci han tal tongan-i kwiyep-ta. baby-TOP born-after one month for-NOM is cute-PAST-DEC' 'A baby is cute for the first month.'

(Lee 2017)

In (5a), the verb miw- 'dislike' is a psychological verb, and it is simplex in that it is not suffixed with the verb ha- 'do' (cf. miw-ha), which behaves like a transitive clause in the case pattern on arguments (Y.J. Kim 1990; K. Kim 2016) (see section 3 for data). With a simplex psychological predicate, an $\mathrm{F}$ adverbial is nominative marked as shown by the adverbial twu pen 'two times' in (5a). Likewise, with an adjectival predicate such as kwiyep- 'cute' in (5b), a D/F adverbial is nominative marked, as shown with the $\mathrm{D}$ adverbial han tal tongan 'one month'.5)

4) An anonymous reviewer mentioned that a locative or manner adverbial can be accusative marked, by providing the data as in (i). I consulted with several native speakers of Korean and the data in (i) were all rejected by them. At the moment, it is not clear whether there is speaker variation among those types of adverbials such as in (i) and (4) or why there is a conflict between (i) and (4). For the purpose of this paper, I follow what has been shown in Wechsler and Lee (1996) in this paper, and I leave the data such as in (i) for future research.

(i) a. Chelswu-ka pap-ul wey ku siktang-eysey-ul mek-ess-ci? Chelswu-NOM meal-ACC why that restaurant-LOC-ACC eat-PAST-QUESTION 'Why did Chelswu eat meal at that restaurant?'

$\begin{array}{llllll}\text { b. Chelswu-ka } & \text { il-ul } & \text { kuli } & \text { yelsimhi-lul } & \text { an } & \text { hay. } \\ \text { Chelswu-NOM } & \text { work-ACC } & \text { so } & \text { hard-ACC } & \text { NEG } & \text { do } \\ \text { 'Chelswu does not work so hard.' } & & & \end{array}$

5) According to an anonymous reviewer, (5a) is better in its grammaticality without nominative case on 
As will be shown in section 4.2 , a D/F adverbial that appears with a psychological verb or an adjectival predicate cannot be accusative marked. More discussion on this issue will appear in section 4.2 .

Although $\mathrm{D} / \mathrm{F}$ adverbials can be either accusative or nominative marked, this paper is concerned with questions of whether accusative case is aspectual or nonaspectual, and of how to syntactically characterize accusative case on those adverbials in the framework of current minimalistic syntax (Chomsky 2000, 2001). Nominative case-marked $\mathrm{D} / \mathrm{F}$ adverbials will be only discussed for comparison to accusative marked ones.

In the literature, animacy has been identified to play a role in having accusative case on D/F adverbials in unaccusative or passive clauses (Kim and Maling 1993; Maling et al. 2001; Kim and Sell 2010; Lee 2017). Although accusative case is normally not available in such clauses, accusative marked $\mathrm{D} / \mathrm{F}$ adverbials are observed in them. This is illustrated in (6) with an unaccusative clause. In (6), the verb nemeci 'fall' is unaccusative and appears with one argument, a subject 'Mina'. The subject is nominative marked. When a $\mathrm{D}$ or $\mathrm{F}$ adverbial such as twu pen 'two times' appears with unaccusative, it is accusative marked as shown in (6).

(6) Mina-ka

Mina-NOM two time $\left(-{ }^{*} \mathrm{NOM} / \mathrm{ACC}\right)$

'Mina fell two times.' nemeci-ess-ta.

fall-PST-DEC

(Lee 2017)

The source of accusative case in unaccusative (6) is thus questionable, and a major factor for accusative case has been identified as animacy of the subject. Accusative case becomes available when there is an animate subject and can be considered agentive. However, there are some data that suggest that inanimate subjects are compatible with accusative marked $\mathrm{D} / \mathrm{F}$ adverbials. This issue will be taken up in section 4.2.

\footnotetext{
the adverbial. On the other hand, another anonymous reviewer mentioned that (5b) may not be grammatical without case marker on the $\mathrm{D}$ adverbial. As for the data in (5b), it is pointed out by the first reviewer that the grammaticality of $(5 b)$ improves if an adverbial such as kacang 'most' is inserted before the adjectival predicate kwiyep-. The judgment reported in Lee (2017) is based on 25 native Korean speakers, as mentioned in section 4.1. Thus, there seems to be speaker variation regarding the data in (5) or other data in this paper. I assume that the differences in grammaticality belong to speaker variation but I do not pursue a question of why such a variation arises.
} 


\section{Non-Aspectual Case on D/F Adverbials}

In this section, I show that accusative case on $\mathrm{D} / \mathrm{F}$ adverbials is syntactic, but not aspectual. This consequence will constitute a basis for the proposed account in section 4 in which the accusative case is the result of an Agree relation couched in the framework of minimalistic syntax (Chomsky 2000, 2001; Boskovic 2009).

Some previous literature suggests that $\mathrm{D} / \mathrm{F}$ adverbials in Korean fall under the domain of syntactic case (e.g., Kim and Maling 1993; Wechsler and Lee 1996; Maling et al. 2001), not semantic case such as inherent or lexical case. In what follows, I discuss some of the core data identified as providing support for this view.6) First, D/F adverbials are observed to show a case alternation similar to a theme object, as shown in (7).

(7) a. Chelsoo-ka I chayk-ul se pen-ul ilk-ess-ta Chelsoo-NOM this book-ACC 3 times-ACC read-PAST-DEC 'Chelsoo read this book three times.'

$\begin{array}{lllll}\text { b. I } & \text { chayk-i } & \text { se } & \text { pen-i } & \text { ilk-hi.eci-ess-ta } \\ \text { this } & \text { book-NOM } & 3 & \text { times-NOM } & \text { read-PASS-PAST-DEC }\end{array}$

'Chelsoo read this book three times.' (Kim and Maling 1993)

The sentence in (7a) is an active clause, and the sentence in (7b) is the passive counterpart of (7a), which is a typical pair where a structural case alternation on a theme object can be observed. The theme chayk 'book' in active (7a) appears as an object, and it is accusative marked. In the passive clause (7b), it appears as a subject and nominative marked. In the same sentences, the F adverbial se pen 'three times' shows the same pattern of case alternation with the theme nominal 'book'. In an active clause (7a), it is accusative marked, and in a passive clause (7b), it is nominative marked.

$\mathrm{D} / \mathrm{F}$ adverbials also pattern with theme objects in that they are not allowed with nominative case in an active clause, as illustrated in (8a) below: the object 'this book' is ungrammatical with the nominative marker, and the same is the case with the $\mathrm{F}$ adverbial se pen 'three times'. Likewise, in a passive clause, accusative case is not

6) As for the reviews of some of the previous analyses, see Sohng (2004) or Lee (2017). For the purpose of this paper, I do not replicate them. 
allowed on D/F adverbials, just like it is not allowed on a theme nominal that appears in the subject position, as shown in (8b).

(8) a. Chelsoo-ka I chayk-ul/-*i se pen-ul/-*i ilk-ess-ta Chelsoo-NOM this book-ACC/-*NOM 3 times-ACC/-*NOM read-PAST-DEC 'Chelsoo read this book three times.'

b. $\mathrm{i}$ chayk-i/ se pen-i/-*ul ilk-hi.eci-ess-ta this book-NOM 3 times-NOM /-*ACC read-PASS-PASS-PAST-DEC 'Chelsoo read this book three times.' (Kim and Maling 1993)

Case marking on a $\mathrm{D} / \mathrm{F}$ adverbial in a transitive clause makes a similar point: it is syntactic, similar to case marking on an object argument, as exemplified in (9).7) In the transitive clause in (9a), for instance, the object pap 'meal' is accusative marked, and the D adverbial han sikan 'one hour' in the same sentence is also accusative marked. Like the object, nominative marking on the adverb is not allowed, as indicated in (9a). The transitive clause in (9b) illustrates the same point.

(9) a. Mina-ka pap-ul/*-i han sikan $-*^{*}$ i/-ul mek-ess-ta Mina-NOM meal-ACC/-NOM one hour -*NOM/-ACC eat-PAST-DEC 'Mina ate (a meal) during one hour.'

(Lee 2017)

b. Chelsoo-ka ku pokose-ul/*-i two pen-*i/-ul kemthoha-yess-ta Chelsoo-NOM that report-ACC/-NOM 2 times-*NOM/-ACC review-PAST-DEC 'Chelsoo reviewed the report two times.'

(Kim and Maling 1993)

In contrast, some intransitives, such as simplex psychological verbs or adjective predicates discussed in section 2 , allow only nominative case on a $\mathrm{D} / \mathrm{F}$ adverbial. Consider first a psychological verb, as illustrated in (10).

7) Verbs such as patta, macta, and tanghata 'get/receive' are also proposed to pattern with transitives (e.g., Maling et al. 2001). Although these verbs indicate a semantically passive meaning, they have the same argument structure as transitives, having a nominative subject and an accusative object. As expected, D/F adverbials that appear with these verbs are accusative marked only. I assume that these are syntactically transitive as with the previous studies. 
(10) Na-nun Mina-ka/-*lul twu pen-i/*-lul miw-ess-ta.

I-TOP Mina-NOM/-*ACC two time-NOM/*ACC dislike (is distasteful)-PST-DEC 'I disliked Mina two times.'

(Lee 2017)

A simplex psychological verb has been treated as intransitive with respect to case marking (e.g., Y.J. Kim 1990, K.K. Kim 2016). This type of predicate allows two arguments like a transitive predicate, as shown in (10); an experiencer subject such as ' $\mathrm{I}$ ', and a theme object like 'Mina' in the same sentence.8) However, unlike a typical transitive (9), accusative case is not allowed on the object, as shown with 'Mina' in (10). Similarly, accusative case is not also allowed on D/F adverbials that appear with this type of the predicate: only nominative case is allowed, as shown with the F adverbial twu pen 'twice' in (10). In Korean, there is another type of psychological verb, which belongs to Class I in the sense of Belletti and Rizzi (1988) (Y.J. Kim 1990, K. Kim 2016). An example of Class I is illustrated in (11).

(11) Nay-ka Mina-*ka/-lul twu pen-*i/-lul miw-ehay-ess-ta.

I-TOP Mina-*NOM/-ACC two time-*NOM/ACC dislike-do-PST-DEC 'I disliked Mina two times.'

In (11), the verb miw - is suffixed with the verb ha 'do', unlike the simplex psychological verb in (10) above. This change in the verb also brings a change in the case marking on the theme object: the object has to be in accusative and cannot be in nominative. In fact, this type of psychological predicate has been proposed to have a transitive structure; moreover, an experiencer subject of this type of predicate is agentive, exhibiting a range of properties of typical agents (Y. J. Kim 1990; K. Kim 2016). If so, with a Class I psychological verb, a D/F adverbial is expected to be marked as accusative, which is borne out by the data in (11): the F adverbial twu pen 'two times' is accusative marked, and cannot be nominative marked. The contrast in case marking on the adverbials between the two different classes of psychological predicates (10) and (11) is consistent with the current proposal that case marking on $\mathrm{D} / \mathrm{F}$ adverbials is syntactic, similar to that on object arguments. In section 4.2, I discuss the stative nature of the psychological predicate type in (10) along with adjectival predicates (see (12) below) with respect to case marking on $\mathrm{D} / \mathrm{F}$ adverbials.

8) In this type of clause, in addition to nominative, an experiencer can be dative marked (Y.J. Kim 1990; K. Kim 2016). 
Turning to another type of intransitive, adjectival predicates, as presented in (12), the predicate in (12) is adjectival and allows one argument only, namely a subject, as illustrated with aki 'baby'. In Korean, with this type of predicate, only nominative case is allowed on the subject. Likewise, D/F adverbials that appear with this type of predicate are allowed with nominative case only, and not with accusative case, as shown with the D adverbial hantal tongan 'for first month'.

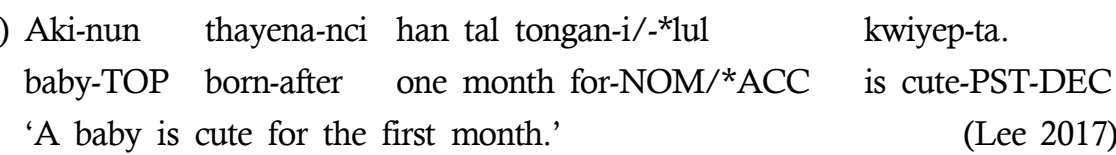

The data discussed thus far suggests that case marking on $\mathrm{D} / \mathrm{F}$ adverbials, if present at all, is syntactic, just like case marking on an object. ${ }^{9)}$ In transitives they have to be accusative marked, while in certain intransitives they have to be nominative marked. Moreover, they exhibit case alternation depending on the voice of the predicate, i.e., active- passive. The pattern of case marking on D/F adverbials suggests that accusative (as well as nominative) case marking on $\mathrm{D} / \mathrm{F}$ adverbials is syntactic, just like the case on an object.

In some languages such as Russian and Finnish where a similar type of adverbial such as a duration or a distance measure adverbial is case-marked, accusative case on the adverbial indicates aspectual properties of an event (e.g., Pereltsvaig 2000, Kylie 2007). In what follows, I discuss Russian data exemplified with distance measure adverbials, but the same account applies to duration adverbials in the language (Pereltsvaig 2000). I also compare D/F adverbials in Korean to those in Russian. It will be shown that case marking on the adverbials in Korean is not aspectual not being associated with boundedness, unlike in a Russian-type language. An example of Russian data is provided in (13). Note that this paper is not proposing that accusative case on an object in Korean is not associated with boundedness, but is proposing that accusative case on $\mathrm{D} / \mathrm{F}$ adverbials is not. ${ }^{10)}$

\begin{tabular}{|c|c|}
\hline (13) Tom & bezhal \\
\hline
\end{tabular}

'Tom ran two miles.'

(Pereltsvaig 2000)

9) Optionality of case marking on D/F adverbials noted in section 2 does not undermine this conclusion, as accusative case on an object in Korean is optional in certain cases.

10) The aspectual properties of objects in Korean need further investigation, which is beyond the scope of this paper. 
Similar to D/F adverbials in Korean, the distance adverbial dve mili 'two miles' in (13) is accusative marked, as reflected on the numerals. In Pereltsvaig (2000), it is proposed that accusative case on this type of an adverbial indicates boundedness of an event, in the sense of Kiparsky (1998). Roughly speaking, an event type of accomplishment is a bounded event, while an event type of activity is an unbounded event. 11) For instance, an 'in X time' phrase, which is compatible with an accomplishment but not with activity, becomes grammatical in the presence of an accusative marked adverbial in Russian, as shown in (14):

$$
\begin{array}{ll}
\text { (14) a. *On begal } & \text { za odnu minute. } \\
& \text { He ran.IMPERF } \quad \text { in one minute } \\
& { }^{*} \mathrm{He} \text { ran in one minute.' }
\end{array}
$$

$\begin{array}{rllll}\text { b. On begal } & \text { petdesjat } & \text { metrov } & \text { za odnu minute. } \\ \mathrm{He} & \text { ran.IMPERF } & \text { fifty.ACC } & \text { meters } & \text { in one minute }\end{array}$

'He ran fifty meters in one minute.'

(Pereltsvaig 2000)

In (14a), the activity predicate begal 'ran' is in an imperfective form. In Russian, the imperfective form of a verb is associated with an unbounded event, in contrast to the perfective form. Thus, the event of his running in (14a) is unbounded, and it is not compatible with an 'in X time' phrase, za odnu minute 'in one minute', which is compatible with a bounded event. In contrast, in (14b), the event of his running becomes bounded with the addition of the distance measure adverbial petdesjat 'fifty meters', as the compatibility with za odnu minute 'in one minute' shows. Building on this type of fact, it is proposed that the accusative marker on adverbials in Russian is assigned from an Asp(ect) head above VP (Pereltsvaig 2000). In particular, this Asp head has $[+\mathrm{B}$ (ounded)] feature and a relevant adverbial that has the same feature merges in the specifier of AspP, as schematically represented in (15).

$$
[\text { AspP } \quad \text { Adv }[+B] \quad \text { Asp' } \quad[\text { Asp }
$$$$
\text { Asp [+B] }
$$$$
\text { [vP }
$$$$
\mathrm{V} \cdots]]
$$

However, in Korean, accusative case on D/F adverbials does not show aspectual property of boundedness, which is also pointed out by Maling et al. (2001), Kim

11) Note that boundedness in Pereltsvaig (2000) or Kiparsky (1998) does not correlate with telicity, another semantic property of aspect, about which I do not go into detail. There is another factor known to affect event boundedness in Russian and Finnish, i.e., properties of nominals. For more detail, see Kiparsky (1998) or Pereltsvaig (2000). 
and Sell(2010).12) Recall that case marking on the adverbials is optional, as shown in (16a). The D adverbial in (16a) can appear without a specific case marker, although it can be marked with accusative case. A test with an 'in X time' phrase as shown in (16b) would not reveal the relevant aspectual property of the event, due to the semantic anomaly (indicated by \# in the gloss) that arises from the use of 'in' and 'for' together.13)

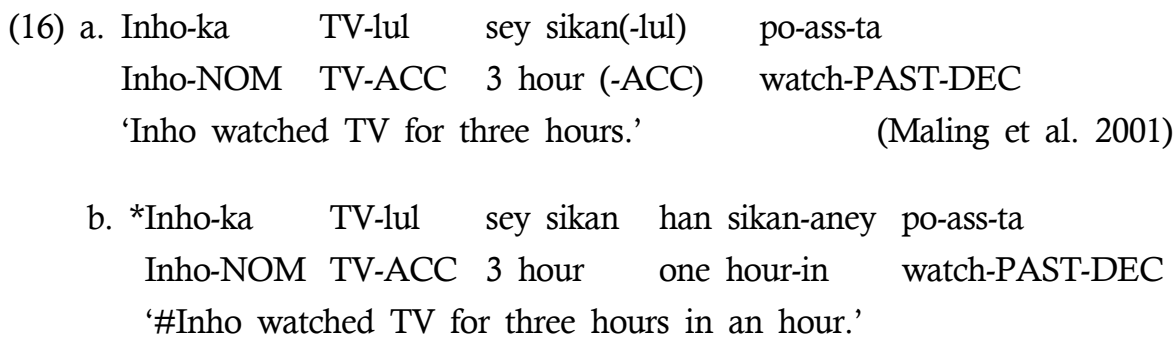

An $\mathrm{F}$ adverbial can also be optionally accusative marked, as in (17a), and may be compatible with an 'in X time' phrase as in (17b). ${ }^{14)}$ However, as the optionality

12) In Korean, there are parallel examples to Russian examples in (14), as illustrated in (i).
(i) a. *ku-nun il-pun-aney tali-ess-ta He-TOPIC one-minute-within run-PAST-DEC

'He ran within one minute.'

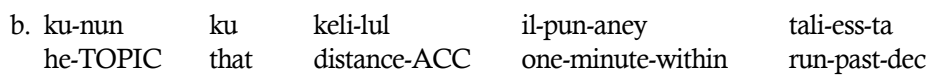

'He ran the distance within one minute.'

As the contrast between (ia) and (ib) shows, (ib) can be interpreted as bounded (or delimited). This is because the sentence in (ib) has an accusative marked object that indicates a distance 'that distance', which is absent in the ungrammatical example in (ia). As mentioned in footnote 10, I do not pursue the aspectual properties of an object in Korean. Also note that the boundedness of the event in (ib) cannot stem from D/F adverbials which are not present in (ib). Thus, the data such as in (i) does not undermine that proposed account of the current paper.

13) It is pointed out by a reviewer that (16b) can be grammatical provided that one of the adverbials is replaced with a PP such as 'in/within a week' that delimits an event, as shown in (i).

$\begin{array}{lllll}\text { (i) Inho-ka } & \text { TV-lul } & \text { ilcwuil-neyey } & \text { sey sikan(-dongan) } & \text { po-ass-ta } \\ \text { Inho-NOM } & \text { TV-ACC } & \text { week-within } & 3 \text { hour(-during) } & \text { watch-PAST-DEC }\end{array}$

'Inho watched TV for three hours within a week.'

The event in (i) is interpreted as bounded or delimited due to the presence of the PP 'within the week', which plays a similar role to 'in X time' phrase in Korean. However, unlike D/F adverbials studied in this paper, the PP 'within a week' cannot be case marked: ilcwril-neyey-*lul/*ka. Thus, the PP type as in (i) is not in the scope of this paper, and I do not further question it. 
of the case marker on the $\mathrm{F}$ adverbial suggests, the compatibility is possible regardless of case on the adverbial. Thus, accusative case on D/F adverbials in Korean cannot be said to indicate an aspectual property of the event such as boundedness, unlike in Russian-type languages. As shown earlier in this section, a case alternation on adverbials in Korean indicates a change in voice, e.g., active-passive, or in transitivity.

$\begin{array}{llll}\text { (17) a. Inho-ka } & \text { TV-lul } & \text { sey pen(-lul) } & \text { po-ass-ta } \\ \text { Inho-NOM } & \text { TV-ACC } 3 & \text { times (-ACC) } & \text { watch-PAST-DEC } \\ & \text { 'Inho watched TV three times.' }\end{array}$
b. Inho-ka TV-lul sey pen han sikan-aney po-ass-ta Inho-NOM TV-ACC 3 times one hour-in watch-PAST-DEC 'Inho watched TV three times in an hour.'

In some studies (e.g., M. J. Kim 2001; Sohng 2004), an accusative marker on D or $\mathrm{F}$ adverbials in Korean is proposed to indicate an aspectual property. ${ }^{15)}$

For example, M. J. Kim(2001) proposes that accusative case on the adverbials indicates event delimitedness, building on the work of Weschler and Lee (1996). In Weschler and Lee (1996), D/F adverbials in Korean are semantically characterized as Situation Delimiters (SDs) which temporally delimit or quantify a given situation denoted by the predicate. ${ }^{16)}$ For example, in (18a), the D adverbial 'for two hours' indicates the duration of the event of running. The adverbial sets a limit on the event of running as two hours. Likewise, in (18b), the F adverb 'two times' quantifies the event of visiting America by setting a limit on the frequency of the event as two times.

14) Instead of -aney, in (16b) and (17b), the phrase 'within an hour' can also be expressed with -man-ey where - man is a delimiter in the language. The native speakers that I consulted generally allow -aney more frequently than man-ey, and thus I keep continue using -aney.

15) In Sohng (2004), following Kim and Maling (1998), Asp in Korean is proposed to license accusative case marking. However, there is no clear account of what aspectual role Asp plays with respect to accusative case marking. In Kim and Maling (1998), Asp has a [ \pm complete] feature and is responsible for accusative case marking. As pointed out in the text in the discussion of M.J. Kim's (2001) study, however, there is no clear correlation between the appearance of accusative case on D/F adverbials and completed semantics of the event.

16) Wechsler and Lee (1996) further characterize SD adverbials as extensive measures in a measurement theory (Luce and Supooes 1993), and in a linguistic sense as in Krifka $(1989,1992)$. This paper does not go into further detail of this notion of extensive measure, and refers readers to the literature. 
(18) a. Tom-i

Tom-NOM twu sikan-tongan-ul

two hours-period-ACC tali-ess-ta.

run-PAST-DEC

'Tom ran for two hours.'

b. Tom-i mikwuk-ul twu pen-ul pangmwun-hay-ss-ta.

Tom-NOM America-ACC two times-ACC visit-do-PAST-DEC

'Tom visited America two times.'

(Wechsler and Lee 1996)

Assuming the status of the adverbials as the SDs, D/F adverbials are proposed to be licensed by an aspectual head such as Asp(ect) that has the [acc, delimited] features (M.J. Kim 2001); a D/F adverbial can be realized with the accusative when the adverb merges in AspP, which is a similar type of analysis to that of Russian discussed above. ${ }^{17)}$

However, in Wechsler and Lee (1996), the accusative case marker is not proposed to be a factor in determining $\mathrm{D} / \mathrm{F}$ adverbials as SDs. What characterizes the adverbials is their semantics as duration or frequency adverbs as discussed above, i.e. being a SD. That is, regardless of the specific case marker, this type of adverbial is semantically an SD. The characterization of $\mathrm{D} / \mathrm{F}$ adverbials as SDs groups them as a type of adverbial that can be marked with a case such as accusative; for example, manner or locating adverbials discussed in section 2 do not belong to the class of SD adverbials, and thus they are not allowed with case marking in Korean (Wechsler and Lee 1996). Moreover, Wechsler and Lee (1996) propose that the accusative case marker on an SD adverbial is assigned when an external argument is present, which is consistent with the current proposal that accusative case on an SD adverbial is not aspectual (see section 4 for relevant discussion).

Building on the discussion in this section, I propose that accusative case marking on $\mathrm{D} / \mathrm{F}$ adverbials in Korean does not correlate with aspectual properties of an event, such as boundedness (or delimitedness), unlike in other languages, e.g., Russian and Finnish, where an accusative case marker on a similar type of an adverbial is taken to indicate a correlation with boundedness of the event denoted by the VP.

17) In M.J. Kim (2001), an aspectual head, DlmP, was proposed (Dlm stands for Delimited). The specific term used for the head is not crucial to the main discussion of this section. 


\section{Analysis: Non-Aspectual Accusative Case, External Argument, and Animacy}

4.1. Non-aspectual accusative case and external argument

In this section, I propose the structure illustrated in (19), which captures the claim that accusative case on $\mathrm{D} / \mathrm{F}$ adverbials is non-aspectual. Building on Wechsler and Lee's (1996) semantic characterization of D/F adverbials as SDs, I propose that the adverbials appear in an AspP that appears above VP. This type of AspP corresponds to a functional phrase proposed under various names (e.g., Inner-AspP in Travis 2010) in the literature for lexical aspect or situation aspect (cf. Tenny 1994). As shown in the previous section, accusative case on the adverbials does not indicate event boundedness. Nevertheless, the adverbials are semantically aspectual, being situation delimiters (characterized as SDs, see section 3), which is one of the semantic properties of aspect (cf. Tenny 1994). I also propose that an Asp head in Korean (19) does not have a case feature to enter an Agree relation with an adverbial that merges in its specifier as a modifier (see below for the discussion for Agree), which captures the fact that accusative case on the adverbials in the language is not aspectual.

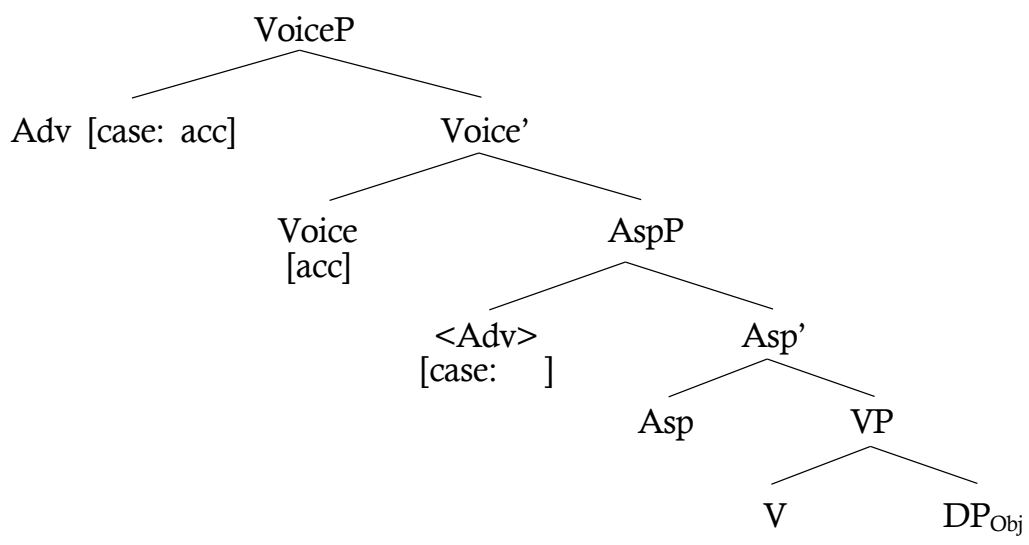

Voice in (19) introduces an external argument, and the argument that merges in the position is interpreted as an agent (Kratzer 1996). ${ }^{18)}$ In particular, as will be

18) Voice in (19) is similar to $v$ in Chomsky (1995) in its function, e.g., bearing an accusative case feature with agentive semantics. The proposal made in this paper does not crucially hinge on the particular names of functional heads. 
shown in this and the next section, an external argument, which can be interpreted as an agent, can be either animate or inanimate in Korean. Although agency implies an animate entity, an inanimate such as a cause can be an external argument that is able to be interpreted as an agent, which will be characterized in terms of teleological capability as proposed in Folli and Harley (2007). Voice in (19) is the locus of the accusative case feature, and accusative case on the $\mathrm{D} / \mathrm{F}$ adverbials is the result of an Agree relation (Chomsky 2000, 2001). Unlike Chomsky (2000), however, I assume that valuing a case feature does not require a phi feature, as with Bošković (2007) and Saito (2016). Despite lacking a phi feature, thus, in (19), an adverbial in AspP can be in an Agree relation with Voice. Furthermore, in Bošković (2007), feature valuation takes place in the probe. In the context of (19), this means that the adverbial with an unvalued case feature in the specifier of AspP raises to the specifier of VoiceP to probe Voice, ${ }^{19)}$ which has an appropriate case feature, i.e., [acc], and case of the adverbial is valued as accusative.20)

Voice with these properties captures the range of data discussed in the previous section: accusative case on $\mathrm{D} / \mathrm{F}$ adverbials becomes available when an external argument- introducing head with an accusative case feature is present. The current proposal is similar to those which also proposed that the presence of an external argument is needed to have accusative case on the relevant adverbials (e.g., Wechsler and Lee 1996; Maling et al. 2001). What this paper newly contributes to the current issue is the formalization of an external argument in a current minimalist syntactic theory that is able to account for the realization of accusative case on $\mathrm{D} / \mathrm{F}$ adverbials. In particular, the previous studies do not detail how an external argument syntactically plays a role in the realization of accusative case on $\mathrm{D} / \mathrm{F}$ adverbials. Note that Voice or a similar type of a head is well recognized for being responsible for accusative case on an object (e.g., Chomsky 1995). However, such a head has not been proposed to be responsible for accusative case on adverbials in Korean

19) An anonymous reviewer mentioned that unvalued case feature on an adverbial in (19) would be valued even when accusative case is not overt, which seems to be so. Also, this line of thought seems to be able to capture the fact that case markers on $\mathrm{D} / \mathrm{F}$ adverbials can be omitted as noted in section 2.

20) Assuming that Korean is a language that allows multiple specifiers, an object will also raise to the specifier of VoiceP. It is in an Agree relation with Voice in terms of the accusative case feature. The structure proposed in (19) seems to suggest that there may be a scope relation between an object and a D/F adverbial. However, it is not clear whether such a relation would exist, similar to the scopal relation between a subject and the adverbial type noted in the literature (see section 4, e.g., (24)). For example, it is difficult to obtain an ambiguity between an object and an adverbial similar to the one between a subject and an adverbial in the literature. For the purpose of this paper, I leave this issue for future research. 
examined in this paper.

Moreover, unlike the previous syntactic approaches to the distribution of $\mathrm{D} / \mathrm{F}$ adverbials, this paper provides a relatively novel look at the locus of $\mathrm{D} / \mathrm{F}$ adverbials in syntax, namely in an AspP that does not bear an [acc] case feature. Under this view, not only the aspectual semantics of $\mathrm{D} / \mathrm{F}$ adverbials can be captured, but also the fact that accusative case on them is not aspectual can be accounted for. ${ }^{21}$ )

Let us look at how the proposed analysis can account for the data discussed in section 3. In that section, it has shown that accusative case on the adverbials is available in a transitive context, such as an active transitive clause, but it is not in a passive clause or a certain type of intransitive. Some of the data are repeated below.

(20) a. Chelsoo-ka i chayk-ul se pen-ul/-*i ilk-ess-ta Chelsoo-NOM this book-ACC 3 times-ACC/-*NOM read-PAST-DEC 'Chelsoo read this book three times.'

b. $\mathrm{i}$ chayk-i se pen-i/-*ul ilk-hi-eci-ess-ta this book-NOM 3 times-NOM/-*ACC read-PASS-PASS-PAST-DEC 'Chelsoo read this book three times.'

(21) Mina-ka pap-ul/*-i twu pen-*i/-ul mek-ess-ta Mina-NOM meal-ACC/*NOM two time -*NOM/-ACC eat-PAST-DEC 'Mina ate (a meal) two times.'

In transitives as in (20a) and (21), Voice with the feature [acc] is responsible for the accusative case on the adverbials via Agree, as just discussed above. In contrast, in a passive as in (20b), a functional head such as Voice with the [acc] feature is not available (e.g., Baker et al. 1989); for example, a passive Voice head is defective, lacking a case feature and a specifier. Thus, accusative case cannot be realized on $\mathrm{D} / \mathrm{F}$ adverbials in examples such as (20b). ${ }^{22)}$

21) An object such as an incremental theme is accusative marked via Asp as is often proposed in the literature. However, it is not necessary to assume in priori that accusative case is reserved for an incremental theme only. As shown in this paper, D/F adverbials in Korean or similar type of adverbials in Russian can be accusative marked even though they are not incremental themes.

22) An unvalued case feature on an adverbial will be valued in a higher position where it scopes over a subject. See footnote 25 for relevant discussion. An anonymous reviewer suggested that accusative case in (20b) is grammatical. However, none of my consultants accept accusative case, and the literature on this issue also clearly mentioned that accusative case is disallowed. I assume that there may be a speaker variation, but does not further question this issue. 
The proposed account can also capture the data with an inanimate subject, noted in the previous literature (e.g., Maling et al. 2001; Lee 2017). Like external arguments of transitives in (20a) and (21), an inanimate subject can appear with accusative marked adverbials, but not with nominative ones, as shown in (22).23)

\section{(22) a. i senincang kkochi-i halwu tongan-ul/*i phi-n-ta this cactus flower-NOM one day for-ACC/*NOM bloom-PRES-DEC 'This cactus flower blooms for one day.'}

b. Hay-ka cali-lul yeltwu sikan tongan-ul/*-i pichwu-ess-ta sun-NOM this place-ACC 12 hours for-ACC/*NOM light-PAST-DEC 'The sun lit this place for 12 hours.' (Maling et al. 2001)

In (22a), the event of blooming is caused by the subject, $i$ senincang kkochi 'this cactus flower', and in (22b), the natural object hay 'sun' acts as a cause of the event of 'lighting this place'. Although not indicated in the morpheme gloss, the verb pichwu in (22) consists of root pich- and a causative suffix $-w u$. The inanimate external arguments are those often described as causes in the literature (e.g., Levin and Rappaport Hovav 1995). Although the previous approaches suggest that these are similar to external arguments of transitives either structurally or semantically, there is no detailed characterization regarding how an inanimate cause in Korean can be viewed as being similar to an external argument of a transitive. I propose that similar to animate external arguments of transitives, these inanimate causes can be viewed as agents, and thus merge in the specifier of VoiceP, as with Folli and Harley (2007). These authors propose that an entity that has teleological capability with respect to the event of which it is predicated can be viewed as an agent, regardless of animacy, and such an entity merges in the specifier of an agentive functional phrase, e.g, Voice. ${ }^{24)}$ Teleological capability is defined as "the inherent qualities and abilities of the entity to participate in the eventualities denoted by the predicate" (Higginbotham 1997). To illustrate, consider sound emission verbs such as 'whistle' in Italian (23a). This verb selects avere 'have' as their auxiliary in the perfect, not essere 'be' as in (23b). In particular, regardless of the animacy of the subject, the auxiliary is always

23) An anonymous reviewer pointed out that the adverbial in (22a) can be nominative marked if the tense of the verb is changed to past such as phi-ess-. Although interesting, I leave it for future research.

24) Folli and Harly (2007) proposed an agentive vP, but a specific name of a phrase does not affect the proposed account in this paper. 
'have'. In (23a), the subject is animate 'John', and in (23b) the subject is inanimate 'the train'.

(23) a. Giaani ha/*e fischiato

'John has/*is whistled.'

b. Il treno ha/*e fischiato

'The train has/*is whistled.'

(Folli and Harley 2007)

Given the fact that inanimate arguments such as in (23b) behave syntactically in the same way as animate arguments as in (23a), an inanimate argument of this type of verb is proposed to be an agent external argument, just like an animate argument as in (23a) (Folli and Harley 2007). According to Folli and Harley (2007), what makes the inanimate type as in (23b) an agent is 'teleological capability' of the inanimate argument. For instance, 'the train' in (23b) is structurally built to whistle, and thus it is characterized to possess an inherent ability to carry out the event of whistling. That is, it has teleological capability to initiate the event described by the predicate. As such, it can be viewed as an agent external argument just like an animate external argument such as 'John' in (23a).

I propose that inanimate external argument in Korean such as in (22) have teleological capabilities with respect to the eventualities denoted by the predicate. In (22a), for example, the inanimate entity 'this cactus flower' has its own capability to bloom. As for 'the sun' in (22b), it has a inherent ability to light the position in question. As such, they are external arguments licensed via Voice, similar to animate agents. So, when an inanimate nominal appears as a subject, accusative case marking on $\mathrm{D} / \mathrm{F}$ adverbials can be realized in the same manner as in transitives. Under the account proposed in this paper (19), the presence of an external argument - either animate or inanimate - is crucial for realizing accusative case, rather than the presence of an animate subject, which has been pointed out as a factor for the presence of accusative case on $\mathrm{D} / \mathrm{F}$ adverbials in unaccusatives or lexical passives (e.g., Lee 2017, see section 4.2 for discussion). This paper does not argue against this view. Animacy does contributes accusative case marking on the adverbials, as it implies agency. However, with inanimate subjects, what this paper proposes is that the contribution of animacy to accusative case should be taken together with the event denoted by the predicate (see Kim and Sell 2010, who propose a similar view) - whether the inanimate entity in question has a teleological capability with respect 
to the event in question. As will be shown with psychological and adjective predicates, this is also the case with animate subjects of those types of predicates.

The proposed account is in line with the previous studies that relate different case markings on D/F adverbials to different scopal interpretation (Maling et al. 2001, Kim and Sell 2010, Lee 2017). In Lee's (2017) survey study with 25 native Korean speakers, for instance, it is confirmed that different case markers on the adverbials indicate the relative scope relation between a subject and a D/F adverbial. When the adverbial is accusative marked, the subject takes a wide scope over the adverbial. For example, in (24), the subject ai 'child' takes a wide scope over the accusative marked adverbial 'two times'. In this case, the available interpretation is that the same child ate a meal twice.
Ai-ka
pap-ul
two pen-*i/-ul
mek-ess-ta
Child-NOM meal-ACC
two time $-* \mathrm{NOM} /-\mathrm{ACC}$
eat-PAST-DEC
'A child ate (a meal) two times.'

In contrast, a $\mathrm{D} / \mathrm{F}$ adverbial takes a scope over a subject when the adverbial is nominative marked. For example, in (24), a nominative adverbial would take scope over the subject if nominative case were available on the adverb. In this case, the sentence in (24) would mean that in each instance of the event of eating a meal, a different child is involved. However, in this sentence, this interpretation is not available, as predicted by the fact that the adverbial cannot be nominative marked. This is also confirmed by the speakers in Lee's study.

In the proposed structure (19) where an external argument merges higher than the adverb, a wide scope of the subject over the adverbial is well expected. Non-availability of the narrow scope is also captured, as the adverbial merges below the subject external argument; thus, nominative case is not available. ${ }^{25)}$ The view that case marking on the relevant adverbs indicates relative scope between the subject and the adverbial is in accordance with the current paper that different case markers do not indicate aspectual differences.

25) Nominative marked adverbials are proposed to merge above the subject (e.g., Kim and Maling 1993, Maling et al. 2001). This type of adverbials is treated being similar to floating quantifiers, and nominative case is the result of case agreement with the subject. I assume this approach for now, and leave the issue of how nominative case on $\mathrm{D} / \mathrm{F}$ adverbials is realized in current syntactic theories for further research. 
This section examines some of the data identified as having accusative case on $\mathrm{D} / \mathrm{F}$ adverbials, even though the predicates are intransitive. Those data typically include unaccusatives and unergatives where a single argument, a subject, is present, but no object is available. In this type of data, the subject is nominative marked and no accusative case is possible. Considering the data of transitives where case marking on $\mathrm{D} / \mathrm{F}$ adverbials patterns with case marking on an object (see section 3 ), it is not clear how accusative case can become available on $\mathrm{D} / \mathrm{F}$ adverbials that appear with these types of predicates. The literature identifies two factors that can make accusative case available on $\mathrm{D} / \mathrm{F}$ adverbials with such a predicate: animacy of the subject and the semantics of the eventuality denoted by the predicate. I discuss animacy followed by the semantics of the eventuality. Consider the data with first type of intransitive, unaccusative (25). Another type of intransitives, unergative predicates, will be discussed subsequently. The predicates in (25) are assumed as unaccusatives in the previous literature, which I also assume in this paper. ${ }^{26)}$

(25) a. han namca-ka hansikan-ul/*-i a man-NOM one hour-ACC/-*NOM 'A man rolled down for an hour.'

b. han namca-ka twu pen-ul/ $*_{-i}$ a man-NOM two CL-ACC/-*NOM fall.down-PAST-DEC 'A man fell down twice.' kwuletteleci-ess-ta

roll.down-PAST-DEC 
the sense of van Valin and Wilkins (1996), which initiate or bring about the event described by the VP, akin to a controller of the event (Smith 1970) or a causer of internally or externally caused eventualities (Levin and Rappaport Hovav 1995). Maling et al. (2001) provide a similar characterization of animate subjects of unaccusatives in terms of volitionality or agency. Under these semantic views, for example, the subject 'a man' initiates or brings about the event of 'rolling down' in (25a) and 'falling down' in (25b). Thus, an animate subject of an unaccusative can be interpreted as an agent, in addition to a theme interpretation (e.g., Maling et al. 2001, Lee 2017). Maling et al. (2001) propose that in the case of an agentive interpretation, externalization of the subject takes place in which the subject of the unaccusative predicate can act as an external argument of the predicate (Maling et al. 2001). In their proposal, externalization means displacing an internal argument of VP to an external position of VP.

In essence, externalization of an internal argument in Maling et al. (2001) suggests that an unaccusative predicate with an agentive interpretation can have a transitive structure, which can be easily translated into the proposed structure (19) in this paper. Note however that this paper does not assume externalization of an internal argument as proposed in Maling et al. (2001): the predicate in (25) is ambiguous having two potential structures such as transitive in (19) or an unaccusative structure. In the former case, a subject is interpreted as an agent because it has teleological capability: it is able to perform the event denoted by the verb phrase. For example, the animate subject 'a man' in (25b) can participate in the event of falling down as an agent, as it has the ability to fall down. As such, it merges in the specifier of VoiceP as an external argument being interpreted as an agent. ${ }^{28)}$ Consequently, in this case, the adverbials are under the scope of VoiceP, which is confirmed by both the available wide scope and the non-available narrow scope readings: it is the same man who fell down twice, and there is no interpretation where a different man was involved in each event of falling down. The wide scope relation between the subject and the adverbials suggests that accusative case on the adverbials is the consequence of an Agree relation between Voice and the adverbial, as discussed in the previous section: the adverbial with an unvalued case feature raises to the specifier of VoiceP to probe Voice, and is valued for accusative case in that position.

28) Otherwise, it will appear in the typical position of a theme, inside VP. In this case, nominative case is available on the adverbial, and the adverbial takes wide scope over the theme. As mentioned earlier, I am abstracting away from the question of how nominative case is realized on the adverbials. 
$\mathrm{D} / \mathrm{F}$ adverbials that appear with another type of intransitive, namely unergatives, are also accusative marked, as illustrated in (26). In (26), ai 'child' is the subject of the event of running, and the D adverbial hansikan 'one hour' is accusative marked. Nominative case is not allowed on the adverbial as indicated in (26). Subjects of unergatives are widely accepted as agents (Levin and Rappaport Hovav 1995, Hale and Keyser 1993), which has been also assumed for Korean (e.g., Maling et al. 2001, Lee 2017). Thus, without further argument, I assume that they are agent external arguments which have a teleological capability to initiate or control the event on their own. This view accounts for accusative case on the adverbials that appear in unergative clauses, in the same manner as in transitives or unaccusatives whose animate subjects are interpreted as agents.
(26) ai-ka
hansikan-ul $/ *_{\mathrm{i}}$
tali-ess-ta
child-NOM one hour-ACC $/{ }^{*} \mathrm{NOM}$
run-PAST-DEC
'The child ran for an hour.'

(Lee 2017)

We now turn to the second factor identified for accusative case marking on $\mathrm{D} / \mathrm{F}$ adverbials in intransitives, namely the semantics of the eventuality - state or non-state - denoted by the predicate. ${ }^{29)}$ It has been recognized that with stative predicates accusative case is not allowed on $\mathrm{D} / \mathrm{F}$ adverbials, even if the subject is animate. Typical data are those adjectival and psychological predicates discussed in section 3. Consider the relevant data in (27). In (27), the subjects are humans - ku malathon senswu 'the marathoner' (27a) and na 'I' (27b) -predicated of the adjective ppal 'fast' (27a), and the simplex psychological verb silh 'hate' (27b). In these examples, the $\mathrm{D}$ adverbial can be nominative marked, but cannot be accusative marked.

29) $\mathrm{D} / \mathrm{F}$ adverbials that appear with the stative verb -iss can be also marked with accusative case (Kim and Sell 2010). Although the verb -iss is typically considered to be stative, Kim and Sell (2010) propose that the verb -iss is a generalized activity verb (cf. Martin 1992) denoting an action or activity, similar to the verb ha-ta 'do' in the language. If so, the accusative case marking on the D/F adverbials with the verb iss can be accounted for by the proposed analysis in this paper. Moreover, the verb is further characterized in terms of categorical/thetic and stage/individual level predicates (see footnote 30 for some discussion). For the scope of this paper, I will leave the characterization of this verb for further research. 
b. na-nun yele hay tongan-i/*-ul ku salam-i/??ul silh-ess-ta

I-TOP several years-for-NOM/*ACC the person-NOM/-? ACC hate-PAST-DEC

'I hated the man for several years.'

(Kim and Sell 2010)

According to Maling et al. (2001), these verbs lack the Action Tier in the sense of Jackendoff (1990). In other words, the subjects of the stative predicates cannot be actors or agents. In terms of this paper, lacking an agent means that no VoiceP is projected for those predicates in (27), even though their subjects are animate. Consequently, the Agree relation required for accusative case cannot be established, and accusative case on the adverbials is not available. The following data (28) provides further support to this view. The data in (28) seems to be similar to (27a) in meaning; however, the adjectival predicate in (27a) is expressed as an adverbial modifier on an activity verb talli 'run' in (28). With this change in the predicate, the duration adverbial is allowed with accusative case marking only, and prohibited with nominative case marking.

(28) $\mathrm{ku}$ malathon senswu-nun chopan tongan- ${ }^{\mathrm{i}} \mathrm{i}-\mathrm{ul}$ paali talli-ess-ta The marathoner-TOP first half for-*NOM/ACC fast run-PAST-DEC 'The marathoner was fast in the first half.' (Kim and Sell 2010)

The contrast between (27a) and (28) suggests that animacy alone cannot affect the case marking on the $\mathrm{D} / \mathrm{F}$ adverbials. Rather, as proposed in section 4.1 , an eventuality denoted by the predicate - state or non-state - should be considered along with animacy of the subject in the determination of the particular case marking on the adverbials. ${ }^{30)}$ In (28), for example, the subject 'the marathoner' is animate and the event expressed by the predicate is initiated by the animate subject; thus, the subject in (28) can be viewed as an agent. Note that this type of data can be understood in terms of 'teleological capability' as discussed in section 4.1. The animate argument in (28) can be viewed to bear teleological capability, i.e., being able to carry out the event denoted by the predicate. In contrast, the animate subject in (27) cannot be said to possess teleological capability, as the predicate is an adjective that describes a state that cannot be initiated by the animate subject.

30) In Kim and Sell (2010), accusative marking on D/F adverbials is available when the predicate in question involves a categorical judgment (Kuroda 1972), which correlates with the notion of stage-level predicate. However, this correlation has been pointed out to be incorrect (Lee 2017). Moreover, Lee (2017) mentions that Kim and Sell's (2010) account does not predict the different scope interpretations with respect to different case marking on the adverbials. I do not further discuss Kim and Sell's (2010) proposal; for details see Lee (2017). 


\section{Conclusion}

This paper examined case-marked D/F adverbials in Korean. Case on these adverbials is shown to be syntactic, consistent with the previous literature. What this paper newly showed is that case on $\mathrm{D} / \mathrm{F}$ adverbials, despite of being syntactic, is not aspectual, as has been proposed for Korean and other languages. Case on these adverbials in Korean is realized non-aspectually via Agree between Voice and a relevant adverb. That is, an Asp head is not a source of accusative case in Korean.

Another issue examined in this paper involves the animacy of external arguments with respect to accusative case on the adverbials. It is shown that the animacy of an external argument is itself not so central in the realization of accusative case. Rather, what is more important is whether a supposed external argument can be viewed to possess teleological capability. The consequences of this paper suggest that accusative case on $\mathrm{D} / \mathrm{F}$ adverbials is different in nature across languages. For example, the locus of accusative case can be different in different languages, being either an Asp head with Russian-type languages, or another head such as Voice, as shown with Korean. An interesting question is why the source of accusative case is different given the fact that accusative appears on the same type of adverbials, duration and frequency, crosslinguistically, which I leave for the next step of research. ${ }^{31)}$

\section{References}

Belletti, Adriana, and Luigi Rizzi. (1988). Psych-verbs and theta theory. Natural Language and Linguistic Theory 6, 291-352.

Baker, Mark, Kyle Johnson and Ian Roberts. (1989). Passive arguments raised. Linguistic Inquiry 20(2), 219-251.

Bošković, Željko. (2007). On the locality and motivation of move and agree: An even more minimalist theory. Linguistic Inquiry 38, 589-644.

Chomsky, Noam. (2000). Minimalist inquiries: The framework. In Roger Martin, David Michaels, and Juan Uriagereka, eds., Step by Step: Essays on Minimalism in Honor of Howard Lasnik, 89-155. Cambridge, Massachusetts: MIT Press.

Chomsky, Noam. (2001). Derivation by phase. In Michael Kenstowicz, ed., Ken Hale: A Life in Language, 1-52. Cambridge, Mass.: MTT Press.

Chomsky, Noam. (1981). Lectures on Government and Binding. Dordrecht: Foris.

31) The difference seems to stem from the property of case marking on an object in language, e.g., being aspectual or non-aspectual. More research is needed to address this issue. 
Chomsky, Noam. (1995). The Minimalist Program. Cambridge, MA: MIT Press.

Folli, Raffaella, and Heidi Harley. (2007). Teleology and animacy in external arguments. Lingua 118(2), 190-202.

Hale, Ken, and Samuel. Jay Keyser. (1993). On argument structure and the lexical expression of syntactic relations. In Ken Hale, Keyser, Samuel. Jay. eds., The View from Building 20, 53-109, MTT Press, Cambridge.

Higginbotham, James. (1997). Location and Causation. MS., University of Oxford, Oxford. Jackendoff, Ray. (1990). Semantic Structures. Cambridge, MA: MIT Press.

Jun, Jong Sup. (2000). Korean has no unique topic or focus marker. Paper presented at 12th International Conference on Korean-Linguistics, Prague.

Kim, Soowon, and Joan Maling. (2001). Accusative adverbials in Korean: Delimiting phrase and Case. Presented at the 23rd North Eastern Linguistics Society of Meeting, New York.

Kim, Soowon, and Joan Maling. (1993). Syntactic case and frequency adverbials in Korean. Harvard Studies in Korean Linguistics V, 368-378.

Kim, Jong-Bok, and Peter Sells. (2010). On the role of eventuality in case assignment on adjuncts. Language and Linguistics 11, 625-652.

Kim, Kyumin. (2016). A unified analysis of existentials and psych-constructions in Korean as pseudo-transitives. Studia Linguistica 70(2), 144-179.

Kim, Young Joo. (1990). The Syntax and Semantics of Korean Case: The Interpretation between Lexical and Semantic Levels of Representation. Ph.D., Harvard University.

Kiparsky, Paul. 1998. Partitive case and aspect. In Miriam Butt, and Wilhelm Geuder. eds., The Projection of Argument: Lexical Compositional Factors. CSLI, Stanford, pp. 265-307.

Kratzer, Angelika. (2004). Telicity and the meaning of objective case. In Jacqueline Gueron and Jacqueline Lecarme, eds., The Syntax of Time, 389-424. Cambridge, Massachusetts/ London, England: The MIT Press.

Kratzer, Angelika. (1996). Severing the external argument from its verb. In Johan Rooryck and Laurie Zaring, eds., Phrase Structure and the Lexicon, 109-137. Dordrecht: Kluwer.

Krifka, Manfred. (1989). Nominal reference, temporal constitution and quantification in event semantics, In Renate Bartsch, Johan van Benthem, and P. van Emde Boas, eds., Semantics and Contextual Expressions, 75-115, Foris, Dordrecht.

Krifka, Manfred. (1992). Thematic relations as links between nominal reference and temporal constitution, In Ivan A. Sag and Anna Szabolcsi, eds., Lexical Matters, 29-53, CSLI Press, Stanford.

Kuroda, Shigeyuki. (1972). The categorical and the thetic judgment: evident from Japanese syntax. Foundations of Language 9, 153-185.

Kylie, Richardson. (2007). Case and Aspect in Slavic. UK: Oxford University Press.

Lee, Eun Hee. (2017). Case alternation in duration and frequency adverbials in Korean: A semantic--pragmatic explanation. Lingua 189-190, 1-18.

Levin, Beth and Malka Rappaport Hovav. (1995). Unaccusativity: At The Syntax-Lexical Semantics Interface. Cambridge, MA: MIT Press. 
Luce, Duncan and Patrick Suppes. (1993). Measurement theory. In Encyclopedia Brittanica Macropedia, vol. 23, 692-697.

Maling, Joan. (1989). Adverbials and structural case in Korean. Harvard Studies in Korean Linguistics, III, 297-308.

Maling, Joan. 1993. Of nominative and accusative: the hierarchical assignment of grammatical case in Finnish. In Anders Holmberg, and Urpo Nikanne, eds., Case and Other Functional Categories in Finnish Syntax, 51-76, Mouton de Gruyter.

Maling, Joan, Jong-Sup Jun and Soowon Kim. (2001). Case-marking on duration adverbials revisited. In Hee-Don Ahn and Nam-Kil Kim. eds., Selected Papers from the Twelfth International Conference of Korean Linguistics, 323-335, Kyungjin Publishing, Seoul, Korea.

Martin, Samuel. (1992). A Reference Grammar of Korean. Rutland: Charles E. Tuttle.

Pereltsvaig, Asya. (2000). On accusative adverbials in Russian and Finnish. In Artemis Alexiadou and Peter Svenonius, eds., Adverbs and Adjunction: Linguistics in Potsdam 6 155-176. Potsdam.

Smith, Carol. (1970). Jespersen's 'move and change' class and causative verbs in English. In Jazayery, Mohamed, Polome, Edgar, Winter, Werner. eds., Linguistic and Literary Studies in Honor of Archibald A. Hill, vol. 2: Descriptive Linguistics. Mouton, Berlin, pp. 101-109. Sohng, Hong-Ki. (2004). A minimalist analysis of adverbial case in Korean. Studies in Generative Grammar 14, 103-136.

Tenny, Carol. (1994). Aspectual Roles and the Syntax-Semantics Interface. Dordrecht: Kluwer. van Valin, Robert. (1990). A synopsis of role and reference grammar. In van Valin, Robert. ed., Advanced in Role and Reference Grammar. John Benjamins, Amsterdam, pp. 1-167.

Travis, Lisa. (2010). Inner Aspect. Dordrecht: Kluwer Academic Press.

van Valin, Robert and David Wilkins. (1996). The case for 'effector': case roles, agents, and agency revisited. In Masayoshi Shibatani and Thomson Sandar. eds., Grammatical Constructions. Oxford University Press, Oxford, pp. 289-322.

Wechsler, Stephen, and Yaek Sheik Lee. (1996). The domain of direct case assignment. Natural Language and Linguistic Theory 14, 629-664.

\section{Kyumin Kim}

Assistant Professor

Department of English Literature and Language

Cheongju University

298 Daeseong-ro Cheongwon-gu, Cheongju-si, Chungcheongbuk-do, Korea

E-mail: kyumin.kim2012@gmail.com

Received: July 4, 2018

Revised: August 11, 2018

Accepted: August 14, 2018 